\title{
Emotion States in Video Game Play: A Study on the Emotional Exhibition of 18-30 Years Old Americans within MOBA Game
}

\author{
Sicheng $\mathrm{Li}^{1, *}$ \\ ${ }^{1}$ School of Communication, Emerson College, Boston 02116, the United States of America \\ ${ }^{*}$ Correspondent author. Email: sicheng_li@emerson.edu
}

\begin{abstract}
Online video games in now widely considered as one of the best activities that entertained people. Multiplayer online battle arena (MOBA), as one of the most popular types of video games, has received a lot of attention. This work aims to study the emotional states of 18-30 years old Americans within and after MOBA gameplay, the reasons for the exhibition of emotions, and the duration of emotions. Results show a mixed state of positive and negative emotion exhibited while playing MOBA games and was closely related to gaming scenes. The researcher recommends that other emotions such as frustration, melancholy, pride, and contempt could be included in future research.
\end{abstract}

Keywords: MOBA games, Emotional experience, Positive emotions, Negative emotions

\section{INTRODUCTION}

Multiplayer online battle arena (MOBA), originally spawning from real-time strategy games, is a strategy video game subgenre in which two teams of players compete against each other on a predetermined battleground. Each player is in charge of a single character with a unique set of powers that progress through time and contribute to the team over plan [1]. The victory condition for each team is to destroy the opponents' main structure, located on the diagonal of the battlefield. Each match of MOBA games (henceforth referred to as MOBAs) starts with two opposing teams, typically made up of five players. Players cooperate to achieve the ultimate goal, which is to destroy their enemy's base while protecting their own from the opposite [2]. By the early 2010s, MOBA has become a big part of the eSports category. More than half $(52 \%)$ of the millions of individuals who explored free-to-play games on PC in 2014 did so with a MOBA [3]. The genre had become a significant element of the esports category by the early 2010 s.

According to market research firm Newzoo, 205 million people watched or participated in eSports in 2014 - meaning that if the eSports nation were actually a nation, it would be the world's fifth-largest nation [4]. While eSports has long been the most popular in Asia, particularly in gaming-crazed Korea, North America and Europe currently have 28 million eSports followers, with the number expanding at a rate of $21 \%$ each year [4]. Major MOBAs such as League of Legends (LOL) and Dota 2 have attracted millions of active monthly unique players worldwide [5]. The world's most popular MOBAs have a big player base. The grand final of the world's largest annual competition, League of Legends Worlds 2019, drew around 4 million peak viewers - and that's before Chinese platforms were factored in. There is no other game in the world with such a large viewership [6]. The League of Legends Championship Series (LCS) is the top level of professional League of Legends run by Riot Games in North America. In LCS Summer LOL Championships, the prize pool reached $\$ 200,000$, and the peak viewers reached 262,025, and the cumulative hours watched were 17,202,330 [7].

Many researchers are interested in how video games can generate emotion and what motivates the player to play video games, but most have a very limited explanation of what emotional response includes and is related to the types of video games. To understand emotional responses more accurately to video games, we must recognize the differences of video game categories, the age of players, and the in-game and aftergame experience. This work aims at studying the audience reception of MOBA games: what kinds of emotions will appear, the reasons for emotion swings, 
and the duration of those emotions while gamers are playing MOBA games.

\subsection{Investigating emotions exhibition in $M O B A$}

Research questions were identified:

RQ1: What kinds of emotions would players experience while playing MOBA games?

RQ2: What kinds of emotions would players experience after playing MOBA games, and how long would those emotions last?

RQ3: How do other possible factors correlate with the appearance of different kinds of emotions?

\section{LITERATURE REVIEW}

With video games playing an increasingly important role in people's lives, many scholars have researched video games and their player experience. Adolescents are known to experience "over-arousal" of their bodies and emotions, a state that is difficult for them to comprehend and regulate but that they must learn to appropriate and incorporate into their identity constructions [8]. Emotional experiences are defined and structured by a dynamic entity known as the "emotional self," [9] shaped by the meanings assigned to bodily sensations. Emotion can be defined as "an inferred complex sequence of reactions to a stimulus including cognitive evaluations, subjective changes, autonomic and neural arousal, impulses to action, and the behavior designed to have an effect upon the stimulus that initiated the complex sequences." $[10]$

Emotions can be classified in numerous ways. The Big Two emotions are often referred to as positive and negative effects. They both relate to emotion super factors, and each, according to Randy J. Larsen and Ed Diener, is made up of multiple subcomponents of various emotional states [11]. The positive effect relates to all high-energy, enjoyable feelings, such as energy, engagement, joy, happiness, love, and excitement [11]. On the other hand, the negative effect relates to unpleasant emotions such as anxiety, dread, hatred, concern, distress, rage, hostility, and disgust [11]

Psychologist Paul Eckman identified six basic emotions that were happiness, sadness, disgust, fear, surprise, and anger; Wilhelm Max Wundt described emotions by three dimensions: "pleasurable versus unpleasurable", "arousing, or subduing" and "strain or relaxation." For emotion classifications in video games, Frome proposed that there are various emotion types to understand the experience of gameplay, including game emotions - the emotions of competition which generated by winning, losing, accomplishment, and frustration; narrative emotions - the emotions based on video game's characters, settings, and events; artifact emotions - a concept developed by Ed Tan, that are generated by people's response to work as an artifact or craft object; and ecological emotions - emotions generated when a player responds to a video game in the same way they respond to the real world [12].

The major function of playing video games is in place for entertainment. MOBAs are suitable for researchers to trace the emotional changes brought by video gameplay since MOBAs have high complexity and unpredictability, asking players to work with the team to gain victory together, requiring players to have communication skills, tactical planning, and execution skills, and corporation skills; sentiments other than joy and happiness may appear to players within and after gameplay. The motivations of gameplay, the emotion, and player experiences related to them are welldocumented. Tyack, Wyeth, and Johnson's findings indicate that the interplay between individuals and the social reality established within the game significantly impacts the MOBA player experience (PX).[13] PX is partially a product of team-based interactions; According to Johnson et al., MOBA players experience more irritation and a decreased sense of autonomy when compared to other game genres, which is likely due to the intense competition with other players [14]. Interviews with MOBA players identified themes of competition, mastery, and teamwork as essential aspects of the genre and these factors contribute to intense ludic and social experience. [13] Videogames provide a common ground for adolescents to form and keep friendships [15]. New relationships developed through online play appear to have the capacity to provide equivalent support to offline relationships [16]. Group flow, a state in which group members have common positive sentiments of task completion, may be facilitated by social play, which is associated with communication, collaboration, and context-relevant awareness of the capacities of others [17].

\section{METHODOLOGY}

In this study, an online survey was designed to gather quantitative data to address these research questions. All respondents in this study were part of a fully representative sample using a sample with $\mathrm{N}=250$ aged from 18-30 years old in the United States, based on a series of screening questions. The survey was administered using Questionpro.com, presented in English, conducted between August 11-15, 2021. Incomplete responses, out-of-age respondents' responses, and responses submitted over a short period $(<100$ seconds) were deleted from the sample. The survey was utilized to gather demographic data, gaming times, and emotions exhibited by MOBA gamers. The statistical tools used in the treatment of data included frequencies, percentages, and Pearson correlation. 
Frequency counts and percentages were used to describe the data. Pearson correlation was used to determine the relationship of certain behaviors and/or scenes and emotions exhibited by the gamers. 0.01 level of probability with $99 \%$ reliability was followed to determine the degree of significance of the findings.

Four questions address RQ1, asking participants about their MOBA experiences: the emotions (i.e., Happiness, Stress, Excitement, Disappointment, Irritation, Delight, Anxiety, Pressure, Boredom) they experienced while they are playing MOBA games and how long would those emotions last. Also, respondents were asked what makes them feel positive and/or negative while playing MOBA games, and possible factors include the entertainment nature of video games, collaborate and communicate with friends/teammates, have a sense of achievement brought by beating enemies, game characters, learn new things, to forget problems, successful tactical planning and execution, compete with better players, consecutive failures, no collaboration and communication within teams, meet toxic players and players who do not do their role well, make bad decisions, strong desire to win, difficulties that player's met to achieve a higher level/rank.

Four questions address RQ2, asking participants about their after-MOBA experiences: the emotions they experienced after they played MOBA games, how long would those emotions last, and what makes them feel positive and/or negative after playing MOBA games. Possible factors include become relaxed and entertained, the feeling of achievement brought by winning, make new friends and/or build new social connections, play MOBA pulls players away from other daily activities (meal, work, sleep, going on a date, etc.), feel empty/unreal, and feel the urge to play more games.

In addressing RQ3, the researcher focused on how demographic and time-related factors correlated with emotional states in MOBA gameplay. We ask about their age (i.e., 18-24 or 15-30), and gender, and employment (i.e., do have a job or do not have a job), and subsequently the extent to which they evaluated their skills by themselves of individual activities (i.e., tactical planning and execution skills, gaming skills, and emotion regulation skills within games) and team-based activities (i.e., communication and corporation skills) when playing with teammates. Value was assessed on a 5-point scale ranging from "Very Poor" to "Perfect". Two survey questions asked about the time spent playing: 'How many hours do you play over a week?' and the frequency of playing - 'How often do you play over a week?' Frequencies for each item included in the questionnaire are shown in the tables.

\section{RESULTS AND DISCUSSION}

In this study, most gamers were aged from 25-30 years old $(\mathrm{f}=162,64.8 \%)$ and in employment $(\mathrm{f}=192$, $76.8 \%) .56 .4 \%(\mathrm{f}=141)$ of them are male and $43.6 \%$ (109) are female. Most gamers $(\mathrm{f}=197,78.5 \%)$ spent less than 12 hours a week playing video games, $22.2 \%$ $(\mathrm{f}=53)$ spent more than 12 hours a week for video games. Most respondents ( $\mathrm{f}=41.9 \%$ ) said they have $4-5$ days for gaming, $25.4 \%$ for 3 days, and $23 \%$ for $6-7$ days. This finding provides a picture of the respondents' gaming behaviour in terms of time expenditures.

In terms of the emotional responses within games of the respondents, Happiness $(\mathrm{f}=196,78.4 \%)$ and Excitement ( $\mathrm{f}=191,76.4 \%$ ) were the top two emotions that young adults experienced while playing MOBA games. These positive emotions signify those gamers were cheerful when they are playing MOBA games. It is interesting to find out that some gamers also felt negative while playing MOBA games. They experienced Pressure $(\mathrm{f}=109,43.6 \%)$, Stress $(\mathrm{f}=92$, $36.8 \%)$, Irritation $(\mathrm{f}=84,33.6 \%)$ and Anxiety ( $\mathrm{f}=72$, $28.8 \%$ ) while playing MOBA games. Stress was the most prominent negative emotion felt by MOBA gamers. These findings show that mixed emotions were shown while playing MOBA games.

Feeling positive within games can be explained by the games' entertaining nature and settings ( $\mathrm{f}=156$, $62.4 \%$ ). As mentioned before, video games are designed for entertaining, and MOBAs have high complexity and unpredictability. These characteristics of MOBAs could make gamers felt exciting. It is not easy to win a game, so having a sense of achievement while beating enemies and competitive players $(\mathrm{f}=141,56.4 \%)$ also contributes to the positive feelings within games. It was significantly correlated with forgetting problems $(r=0.28, p<0.01)$. When gamers were focusing on the game content and achieved something in the games, they can forget about problems and frustrations in the real-life. Further, MOBAs require players to work with the team collaboratively and use strategies to have a better gaming experience, as some respondents were claiming that successful tactical planning and execution within games $(\mathrm{f}=126,50.4 \%)$ and the collaboration and the communication process with teammates, that could be friends or strangers, $(\mathrm{f}=119,47.6 \%)$ brought them positive emotional responses.

Gamers play games for entertain, but if some factors interrupt their positive feelings, negative emotion responses showed up. The top cause of negative feelings within games was meeting toxic players who constantly creates a bad atmosphere which interferes with others' gaming experiences $(\mathrm{f}=148,59.2 \%)$, which was significantly correlated with stress $(r=0.21, p<0.01)$, anxiety $(\mathrm{r}=0.20, \mathrm{p}<0.01)$, pressure $(\mathrm{r}=0.29, \mathrm{p}<0.01)$, disappointment $(\mathrm{r}=0.30, \mathrm{p}<0.01)$, and irritation $(\mathrm{r}=0.32$, $\mathrm{p}<0.01)$. Also, having consecutive failures $(\mathrm{f}=134$, $53.6 \%)$ was significantly correlate with stress $(r=0.29$, $\mathrm{p}<0.01)$, disappointment $(\mathrm{r}=0.42, \mathrm{p}<0.01)$, irritation 
$(\mathrm{r}=0.32, \mathrm{p}<0.01)$, anxiety $(\mathrm{r}=0.24, \mathrm{p}<0.01)$, and pressure $(\mathrm{r}=0.39, \mathrm{p}<0.01)$. Making bad and incorrect decisions in games $(\mathrm{f}=95,38 \%)$ was significantly correlate with stress $\quad(r=0.24, \quad p<0.01)$, disappointment $\quad(r=0.26$, $\mathrm{p}<0.01)$, irritation $(\mathrm{r}=0.33, \mathrm{p}<0.01)$, anxiety $(\mathrm{r}=0.27$, $\mathrm{p}<0.01)$, and pressure $(\mathrm{r}=0.33, \mathrm{p}<0.01)$. The findings indicate that these are all contributors to the negative emotional responses. Interestingly, having strong desire to win $(\mathrm{f}=78,31.2 \%)$ is another factor that brings negative feelings in games and was significantly correlated with competing with better players $(r=0.25$, $\mathrm{p}<0.01)$.

Dr. Jill Bolte Taylor, a Harvard brain scientist, claims that it just takes 90 seconds to identify an emotion and allow it to dissolve while you simply notice it. [18] The survey results show that gamers' feelings may last for a longer period. $31.2 \%(\mathrm{f}=78)$ of respondents said that their emotions within games would last until they stopped playing, and $33.6 \%$ ( $\mathrm{f}=84$ ) said it would last less than 30 minutes after they stopped playing the game. This is reasonable to assume that the gamers may just choose to stay in that emotional loop. The fast-changing game process does not give gamers enough time and attention to dissipate their negative emotions when noticing them.

Happiness and Excitement are also the top two emotions that most of the respondents experienced after the game. Still, the response percentages are lower than the in-game experiences, cited by $70.8 \%(\mathrm{f}=177)$ and $46 \%(\mathrm{f}=115)$. Only $5.6 \%$ ( $\mathrm{f}=14$ ) of respondents said they have no feelings after the games. Negative feelings such as Stress ( $\mathrm{f}=43,17.2 \%)$, Disappointment $(\mathrm{f}=46,18.4 \%)$, Irritation $(\mathrm{f}=44,17.6 \%)$, Anxiety $(\mathrm{f}=32,12.8 \%)$, Pressure $(\mathrm{f}=35,14 \%)$, and Boredom $(\mathrm{f}=28,11.2 \%)$ also shown up after MOBA gameplay. Overall, positive feelings after games were more usual among MOBA gamers. The main reason for feeling positive after games was the amusing nature of MOBA game settings, making gamers become relaxed and entertained after playing it $(\mathrm{f}=143,57.2 \%)$. Team-based games give a chance for the gamers to make new friends and/or build social connections that also make people feel good ( $f=106,42.4 \%$ ). Further, the feeling of having a sense of achievement when winning the game will last for a longer period. Gamers would still respond positively $(\mathrm{f}=143,57.2 \%)$ after stop playing the game. Although games are for entertainment and a lot of gamers said they were enjoyable playing MOBA games, approximately $45 \%(\mathrm{f}=70)$ of the respondents said that they feel negative after playing MOBA games because it pulls them away from other daily activities, such as having meals, working, sleeping, going on a date. Thirty-seven percent $(\mathrm{f}=92,36.8 \%)$ of the respondents said they felt the urge to play more games, which brought them negative feelings. In addition, the feelings of emptiness and unreal after playing MOBA games $(\mathrm{f}=70,28 \%)$ contribute to the negative feelings after gameplay. $16.4 \%$ of respondents said they do not have negative feelings after playing MOBA games. It is also interesting to note that $43.2 \% \quad(\mathrm{f}=102)$ said their emotions after the game only last less than 30 minutes, and $37.3 \%(\mathrm{f}=88)$ said their emotions would last 1-2 hours, which these emotions did somehow carry over in the gamers' actual lives and interfered gamers' daily activities at a certain extent and interfered gamers' daily activities at a certain extent.

The findings of the study are theoretical and practically meaningful. From the theoretical point of view, the results show that MOBA gamers could feel positively and negatively at the same time while playing MOBA games, and these emotions could be dependent on one another. Form the practical aspect, these results could offer suggestions for gamers and game producers. Gamers can be cautious about their emotional changes and fluctuating while playing MOBA games and practicing self-regulation. Games are designed for entertainment. If gamers feel negative while playing games, they should consider doing something else instead of continuing playing games. Also, MOBA gamers should be aware of the game environment since it is a team-based strategic game. Do not behave negatively to destroy other player's gaming experience. Gamer designers can learn about the gamers' emotional responses within and after gamers and the reasons for those feelings. As a reference, game designers and companies are encouraged to design or improve game settings to let gamers feel more positive when playing MOBA games. For example, designers can improve the game environment by enhancing the banning and reporting system to severely punish toxic players. They can also think about the rank matching mechanism when players were experiencing consecutive failures, which the real-time game dataset can learn. When the failure times come to a specified number, the system can automatically send out a message recommending gamers stop playing the game to prevent the growth of negative emotions.

\section{CONCLUSION}

Based on the findings presented, MOBA players may experience both positive and negative emotions while playing MOBA games. Those emotions would last for a while and somehow interfere with real-life activities. The study also provides some information about what induces MOBA gamers' emotions, including gamers' in-game behaviours. The study recommends future research into various forms of emotions such as frustration, melancholy, pride, and contempt. It is also worth studying gamers' emotional responses and reactions, specifically when they experienced a game defeat or consecutive failures. 


\section{REFERENCES}

[1] Cannizzo, A., \& Ramírez, E. (2015). Towards procedural map and character generation for the moba game genre. Ingeniería y Ciencia, 11(22), 95-119.

https://doi.org/10.17230/ingciencia.11.22.5

[2] How mobas took over gaming. IGN Middle East. (2013, August

1). https://me.ign.com/en/pc/70142/feature/howmobas-took-over-gaming.

[3] Grubb, J. (2015, March 31). League of Legends, Dota 2 will lead PC Gaming's fastest-growing sector to $\$ 500 \mathrm{M}$ this year in North America. VentureBeat.

https://venturebeat.com/2015/03/30/league-oflegends-dota-2-will-lead-pc-gamings-fastestgrowing-sector-to-500m-this-year-in-northamerica/.

[4] Ben Casselman, F. T. E. (2015, May 22). Resistance is futile: Esports is massive ... and growing. ESPN. https://www.espn.com/espn/story/_id/13059210/es ports-massive-industry-growing.

[5] Volk, P. (2016, September 13). League of Legends now boasts over 100 million monthly active players worldwide. The Rift Herald. http://www.riftherald.com/2016/9/13/12865314/mo nthl.

[6] Escharts.com. (n.d.). League of Legends (LOL) Esports Tournaments STATISTICS: ESPORTS CHARTS. League of Legends (LoL) Esports Tournaments Statistics | Esports Charts. https://escharts.com/tournaments/lol.

[7] Escharts.com. (n.d.). LCS summer 2021 detailed VIEWERS stats: ESPORTS CHARTS. detailed viewers stats | Esports Charts. https://escharts.com/tournaments/lol/lcs-2021summer.

[8] Michel, G., Le Heuzey, M. F., Purper-Ouakil, D., \& Mouren-Siméoni, M. C. (2001). Recherche de Sensations ET CONDUITES À Risque chez l'adolescent. Annales Médico-Psychologiques, Revue Psychiatrique, 159(10), 708-716. https://doi.org/10.1016/s0003-4487(01)00123-8

[9] Irvine, L., \& Lupton, D. (1999). The emotional self: A sociocultural exploration. Contemporary Sociology, 28(6), 700. https://doi.org/10.2307/2655565

[10] Plutchik, R. (1982). A psychoevolutionary theory of emotions. Social Science Information, 21(4-5),
529-553.

https://doi.org/10.1177/053901882021004003

[11] Baumeister, R. F., \& Vohs, K. D. (2007). Independence of positive and negative affect. In Encyclopedia of social psychology (Vol. 1, pp. 469-471). SAGE Publications, Inc., https://www.doi.org/10.4135/9781412956253.n278

[12] Frome, J. (n.d.). Eight ways Videogames Generate emotion - digra. http://www.digra.org/wpcontent/uploads/digital-library/07311.25139.pdf.

[13] Tyack, A., Wyeth, P., \& Johnson, D. (2016). The appeal of moba games. Proceedings of the 2016 Annual Symposium on Computer-Human Interaction in Play. https://doi.org/10.1145/2967934.2968098

[14] Johnson, D., Nacke, L. E., \& Wyeth, P. (2015). All about that base. Proceedings of the 33rd Annual ACM Conference on Human Factors in Computing Systems.

https://doi.org/10.1145/2702123.2702447

[15] Colwell, J., Grady, C., \& Rhaiti, S. (1995). Computer games, self-esteem and gratification of needs in adolescents. Journal of Community \& Applied Social Psychology, 5(3), 195-206. https://doi.org/10.1002/casp.2450050308

[16] Trepte, S., Reinecke, L., \& Juechems, K. (2012). The social side of gaming: How playing online computer games creates online and offline social support. Computers in Human Behavior, 28(3), 832-839.

https://doi.org/10.1016/j.chb.2011.12.003

[17] Kaye, L. K. (2016). Exploring flow experiences in cooperative digital gaming contexts. Computers in Human Behavior, 55, 286-291. https://doi.org/10.1016/j.chb.2015.09.023

[18] Stone, A. M. (2020, November 12). 90 seconds to emotional resilience. Alyson M. Stone, PhD, CGP. https://www.alysonmstone.com/90-seconds-toemotional-resilience/ 